\title{
Sustainability of e-Learning Environment: Can Social Presence Be Enhanced by Multimedia?
}

\author{
Hwang-Ji Lu
}

\begin{abstract}
With the exponential development of Internet, distance learning has become an alternative means of taking a course or earning a degree. Social presence is a critical factor for forming and sustaining learning communities that support deeper learning through knowledge sharing. Social presence does not happen spontaneously and is in need of cultivation. This paper explores a review of the literature on social presence and the use of multimedia in distance education. The review of literature indicates that the advent of technological innovation in communications provides new mechanisms and opportunities in the distance learning environment. The findings from the literature review suggest that with the integration of multimedia into classrooms, instructors can increase social presence, enrich student's learning experience and raise student's satisfaction to reduce time and physical barriers existing in the online learning environment.
\end{abstract}

Index Terms-Distance learning, social presence, multimedia, learning community, adult learner, teaching presence.

\section{INTRODUCTION}

Distance education methodologies have come into prominence during the last decades of the 20th century. This article will provide an overview of the concerns in the domain of online instruction. The contemporary community of inquiry model with an emphasis on social presence, teaching presence, and a sense of community will be discussed. It will review the evolution of social presence theory and past research pertaining to the impact of social presence on student's learning. It will also examine the literature concerning strategies for raising social presence and teaching presence. Finally, the practical uses of multimedia will be presented to enhance social presence and teaching presence in the online classrooms.

\section{ONLINE EDUCATION AND ADULT LEARNERS}

The convergence of the need for continuous learning and rapid technological developments have driven distance education approaches to the forefront of educational practice [1], [2]. A large number of online or web-based courses are offered to target adult learners.

Distance learning attracts adult learners who might not otherwise have the opportunity to attend classes on the physical campus due to job and family demands as well as other life commitments. Taking an online course enables learners to participate at different times from different

Manuscript received June 1, 2015; revised January 15, 2016.

Hwang-Ji Lu is with Ashford University, USA (e-mail: hwangji.lu@Ashford.edu). locations. Because of the convenience and flexibility of online learning, more and more adult learners are able to find the balance between their learning goals and busy lifestyles [2]-[4]. Without a doubt, online courses, online degree programs, and virtual universities have proliferated rapidly in the past few decades.

Adult learners enroll in online classes for these four main reasons: cost-saving, convenience, flexible schedule, and work-life-school balance. Although online learning provides numerous advantages, adult learners may face significant challenges in developing a new set of skills for this type of instruction [5], [6]. Currently, colleges and universities utilize learning management systems, such as Blackboard, eCollege, and Moodle, to deliver online courses, providing primarily text-based learning experiences. Within a learning management system, numerous icons, links, text files, and discussions threads are commonly adopted as the course contents and online instructions [4], [7]. Learners study in such an environment without a face-to-face contact with an instructor or their peers since opportunities for those interactions are often limited due to physical separations [7]-[9]. The potential downsides of online learning revolve around the lack of personal interaction between the instructor and student, as well as the student-to-student contact. Limited physical presence and inadequate communication between instructors and students in the online learning environment could, eventually, result in students' frustration, dissatisfaction, less engagement--or even higher dropout rates [2]-[4], [7].

\section{A SENSE OF COMMUNITY}

In the recent years, research studies [7], [10], [11] have gone beyond the definition of distance as a physical proximity in the online education, approaching the concept of distance as a psychological dimension. Gallagher-Lepak, Reilly, and Killion argued that emotional connectedness is a critical factor in setting the tone for feeling a sense of community, building confidence, and reducing the sense of isolation and disconnection [12]. Conrad [13] delineated a sense of community as "a general sense of connection, belonging and comfort that develops over time among members of a group who share purpose or commitment to a common goal" (p. 2). Based upon the attributes of the online learning community, Shea, Li, Shawn and Pickett [14] contended that "a sense of shared purpose, trust, support, and collaboration-i.e., a sense of community-is an essential element in the development of quality online learning environments" (p. 70). In the online education, the learning community offers an opportunity to engage in rewarding learning experience; having a sense of 
community help students learn and retain the knowledge [2], [13]. The cohesiveness of the learning community relies on the development of meaningful social relationships and members' perception of their mutual dependence on each other to achieve community goals [15]. Deeper learning takes place once members in the learning community have common expectations and goals, develop a sense of belonging and connectedness, depend on each other, and cooperate with each other. Consequently the learners' satisfaction and retention rate will increase [16].

\section{SOCIAL PRESENCE}

\section{A. The Evolution of the Theories}

The notion of social presence is widely discussed in the context of mediated communication. Indeed, it has its original roots in the non-mediated interactions-especially in the social psychological theories of interpersonal communication and symbolic interactionism [7]. Social presence can be traced back to Argyle and Dean's [17] concept of intimacy and Wiener and Mehrabian's [18] notion of immediacy. Intimacy is a joint function of eye contact, physical proximity, familiarity of topics, and smiling, all of which develop an equilibrium for intimacy [17]. Immediacy is defined as communication behaviors that enhance closeness to nonverbal interaction as well as nonverbal cues such as facial expression, eye contact, and body movements that could bring about more intense and immediate interactions [18].

Social presence theory was first officially coined by Short, Williams, and Christie in their book, discussing the social psychology of telecommunication and explaining the effects a communication medium that has on the way how people communicate [19]. On the basis of Short, Williams, and Christie's definition, social presence is the 'degree of salience of the other person in the interaction and the consequent salience of the interpersonal relationships' (p. 75). In Short, Williams, and Christie's view, the effect of media per se is the most prominent factor in regulating the degree of social presence that participants develop and share through the mediated communication environment. The concept of social presence has progressively developed with the wide adoption of computer-mediated communication (CMC) and online education. Unlike Short and colleagues, Garrison, Anderson and Archer [20] defined social presence as "the ability of participants in a community of inquiry to project themselves socially and emotionally, as 'real' people (i.e. their full personality) through the medium of communication being used" (p. 94). Garrison, Anderson and Archer debated that participant's personal perception matters more than the medium capability [20]. According to the characteristics of online learning, Tu and McIsaac [6] redefined social presence as "the degree of feeling, perception, and reaction to another intellectual entity in the computer-mediated communication environment" (p. 146). Being social presence implies not only being with another, but also connected or engaged with others in some form of exchange.

\section{B. The Importance of Social Presence in the Learning Community}

Learning is a social process. Social interaction is a prerequisite for collaboration that is essential for learning [6], [7]. Social presence is "a measure of the feeling of community that a learner experiences in an online environment" [6]. Social presence is a requirement for forming and maintaining a sense of community and cognitive presence [10], and the degree of it determines how well the members of a learning community relate to each other on a personal level. During the learning process, learners establish the social infrastructure by which they present themselves, become familiar with other's characteristics, qualities and inner states, and understand the knowledge that other members bring to the community [9], [14]. Social presence is also the basis for developing meaningful interpersonal communication and relationships, which facilitates learners to share knowledge during the learning process. In the online learning community, a high degree of social presence is needed to sustain relationships on the basis of mutual trust that supports the knowledge sharing among the community members. Thus, increased social presence leads to a better person's perception, belonging, and learning in the online community.

\section{Past Research about the Impacts of Social Presence on Student's Learning}

In an educational context, social interaction has multiple facets that include the relationships between instructor and individual student as well as between the student and his/her peers in the overall learning community. In the online learning communities, social presence is critical to enhancing and fostering online social interaction [2], [7], [9]. Since the online education has its increasing popularity and becomes an indispensable part of education, the impact of social presence on student's learning must be examined and understood in developing the social aspect of learning communities. It is extremely important that we understand how students and teachers as well as students and students socially interact in the online classrooms.

In the past few decades, numerous studies have been carried out to investigate the relationships between social presence and various aspects of online learning [4], [13], [21]-[28]. The study conducted by Polhemus, Shih, Richardson and Swan [21] showed that a high degree of social presence would initiate and sustain a greater quantity of interactions and promote deeper interactions. A strong relationship between students' perceptions of their interaction and the quality and quantity of their learning was identified in Picciano's research [22]. Focusing on perceived learning, Richardson and Swan's research revealed that students who have a high degree of social presence in the online classroom tend to be more satisfied with their instructor; furthermore, they confirmed a link between students' satisfaction with their instructor and perceived learning [23]. Russo and Benson's study also obtained a significant relationship between student's satisfaction with learning and instructor presence as well as a stronger relationship between student's satisfaction and the perceived presence of other students [24]. Therefore, they suggested that it is important for both instructors and students to establish and maintain social presence in online learning environments.

Social presence is a powerful predictor of the satisfaction 
that students experienced in their online learning. Two research studies conducted by Cobb [25] and Mayne and $\mathrm{Wu}$ [4] to explore the effectiveness of social presence in predicting student's satisfaction in the online environment found that student's feelings of belonging, comfort, connectedness, and trust are significantly influenced by the instructors' teaching strategies. Other studies indicated that a lack of instructor's social presence, a critical factor measuring the instructor's effectiveness, results in a higher level of student's frustration [26] and a lower degree of affective learning [27]. Conrad's research study reported that teaching presence directly contributes to student's engagement in coursework [13]. Ghamdi, Samarji and Watt investigated teacher immediacy in a virtual learning environment. The results from their study revealed a significant positive correlation between teacher immediacy and students' participation and satisfaction [28].

\section{TEAChING PRESENCE}

Theoretically and empirically, each member in the online learning community has the responsibility to establish and maintain social presence. Nevertheless, the instructor bears more responsibilities to initiate and sustain social presence in the online environment [20], [27], [28]. This additional responsibility is a vital function of an instructor and often understood as teaching presence. Teaching presence was first discussed by Garrison, Anderson, and Archer [20] as one of the three key elements of the community of inquiry framework. Garrison et al [20] defined teaching presence as "the design, facilitation, and direction of cognitive and social process for the purpose of realizing personally meaningful and educationally worthwhile learning outcomes" (p. 5). The facilitation function is the leading contributor to a sense of community and learning. Social presence addresses the basic needs for security and belonging in a learning community. It is the instructor's responsibility to create a space for social interaction and an opportunity for a learning community to form [27]. Keeping students engaged in the course is an imperative role of an effective instructor. It is also important for the instructor to model expected behavior and foster an appropriate learning climate in the online environment where members of the learning community feel comfort, respected, and safe to express and exchange their thoughts and/or opinions. Accordingly, a higher level of satisfaction is achieved and a meaningful, deeper learning process is occurred. Garrison, Anderson, and Archer [20] argued that a high level of teaching presence leads to a positive impact on student's satisfaction, motivation, and consequently on student's engagement in active learning.

Instructor immediacy is the social interaction between teacher and student [28], [29], which is a critical facet of the overall domain of social interaction. Rovai [16] stated that instructor immediacy is the immediate verbal and non-verbal communications-for example-eye contact, smiles, head nods, humor, and use of inclusive language, all of which can lessen the psychological distance between instructors and their students, leading directly or indirectly to greater learning. Instructor immediacy has an influence on student's motivation, and yet student's motivation has a direct impact on student learning [28], [29]. In the traditional face-to-face classroom setting, the instructor can easily transmit the verbal and non-verbal communications to the students in the close physical proximity [29], [30]. On the contrary, in the primarily text-based online environments, there are many challenges to develop social presence due to the lack of verbal and non-verbal cues found in a close proximal setting [28], [29]. Mostly instructors consider it is a challenge to create a sense of community in which students feel connected to be a part of the learning environment.

Despite the fact that CMC lack of social cues, instructors can engage students and stimulate students' social presence because social interaction and community building do not automatically occur [2], [8], [27]. Instructors are crucial to maintaining the interest, motivation, and engagement of students in course activities [2], [20]. Social presence must be constantly and intentionally nurtured through instructors in the online classroom [2]. Unquestionably, social presence, can be cultivated by creative strategies. There must be explicit strategies or techniques aimed at promoting social presence.

\section{StRategies to Riase Social PRESEnCE AND Teaching PRESENCE}

\section{A. Survey of Strategies in the Literature}

Specializing in teaching and learning models for postsecondary minority and nontraditional students, Aragon [1] offered strategies to increase social presence in the online environment and conceptualized three groups of individuals in the online settings: course designers (course design), instructors (delivery and management), and participants (participation) as listed in Table I. Developing welcome messages, including student profiles, incorporating audio, limiting class size, and structuring collaborative learning activities are Aargon's five suggested strategies for course design. Aragon [1] recommended nearly the same strategies for both instructors and participants as he deemed both are important to establishing and maintaining social presence within online communities. However, Aragon differentiated between instructor strategies (e.g., providing frequent feedback, addressing students by name, and allowing students options for addressing the instructor) and participant strategies (e.g., using appropriate titles).

Aragon's framework of creating social presence in the online classrooms has served as a concrete foundation for further research in years to come. Other researchers and scholars have suggested practical guidelines for designers and instructors to develop a community-building climate as well. For example, Swan and Shea [15] highlighted the importance of the careful design of discussion and recommended that designers and instructors should "seek ways to evoke personal experience in discussion" (p. 131). Koh, Kim, Butler and Bock [31] noted the importance of complementing text, which is the dominant form of communication in online communities, with appropriate audio, graphical, and video interfaces such as video chat. Tu and McIssac [6] advised that designers need to select communication channels that 
“optimize the learner's self-image and enhance his/her interaction" (p. 147). In terms of best practices for creating a sense of community, examples include having students and instructors post photographs of themselves, composing and sharing biographies among instructors and students, encouraging interactions through teamwork, and allowing communications and opportunities to share challenges and accomplishes [4], [12].

TABLE I: AARGON'S STRATEGIES FOR SUSTAINING SOCIAL PRESENCE

\begin{tabular}{|c|}
\hline $\begin{array}{l}\text { Course Designers } \\
\text { - develop welcome messages } \\
\text { - Include student profiles } \\
\text { - Incorporate audio } \\
\text { - Limit class size } \\
\text { - Structure collaborative learning activities }\end{array}$ \\
\hline $\begin{array}{l}\text { Instructors } \\
\text { - Contribute to discussion boards } \\
\text { - Promptly answer emails } \\
\text { - Provide frequent feedback } \\
\text { - Strike up a conversation } \\
\text { - Share personal stories and experiences } \\
\text { - Use humor } \\
\text { - Use emoticons } \\
\text { - Address students by name } \\
\text { - Allow students options for addressing the } \\
\text { instructor }\end{array}$ \\
\hline $\begin{array}{l}\text { Participants } \\
\text { - Contribute to discussion boards } \\
\text { - Promptly answer emails } \\
\text { - Strike up a conversation } \\
\text { - Share personal stories and experiences } \\
\text { - Use humor } \\
\text { - Use emoticons } \\
\text { - Use appropriate titles }\end{array}$ \\
\hline
\end{tabular}

\section{B. The Use of Multimedia to Enhance Social Presence and Teaching Presence}

Multimedia is defined as the use of a combination of multiple modes such as audio, graphics, sound, text, and video to convey information [5], [25], [32]. Multimedia technology enables instructors to present the information in various media via sound, text, animation, video, and image [3], [5], [32]. Multimedia can be a very effective medium of delivering information because the combination of these various media fosters a stimulating environment for retaining the information delivered [5], [11], [33]-[35]. Multimedia can be also used to augment social presence and teaching presence in various ways.

Picture/image. A picture is worth 1,000 words if it is used appropriately to deliver the messages. Graphics can help students grasp more complex concepts easier and faster than the written words alone [36]. Graphics convey messages instantly and can be used when the instructor facilitates the dialogue in the discussion forums. Graphics also can be used to improve the information presented in the course shell, announcements, and/or discussion boards.

Sound. Human voice does foster social presence and is the best way to attract attention [5]. Simple sound output can be utilized to draw student's attention in the course delivery [36]. Nowadays it is possible to make simple digital voice recording on a number of devices. For instance, instructors may supply additional learning material by recording audio podcasts for students to download and review at any time that fits them the best. Moreover, instead of providing written feedback, instructors may utilize verbal feedback in the online learning environment. Some universities have the custom-made learning management systems that hold such a capacity of recording verbal feedback in the gradebook. Even without this built-in function, the instructors may record the verbal comments and attach the voice file in the gradebook. In the same vein, the instructors can add a voice file onto the written announcements that may or may not contain corresponding graphics.

Video. Unquestionably, video generates a much greater amount of interest and enjoyment than the traditional text-based material. Video is not just imperative for enriching the level of teaching presence, but also plays a significant role in establishing teacher immediacy in online instruction [10], [29], [37], [38]. Video provides students and instructors with verbal and non-verbal cues that exist in traditional face-to-face environments. Instructional video mode of information delivery helps students see and hear their instructor and makes the online course a more enjoyable learning experience, which in turns facilitates instructor immediacy and establishes the instructor's social presence [10], [29], [37]. Audiovisual technologies such as teleconferencing and webcams can be used in the online environment synchronously and asynchronously. Instructors may take advantage of conferencing software for example Adobe Connect, Blackboard Collaborate, or Citrix GoToMeeting to deliver a simple and cost-effective chat or mini lecture with enjoyable personal interactions.

The best practice of student-centered instruction encourages the instructors to build the rapport with students in the inception of the course. In light with this tenant of student-centered instruction, the instructor and students in the learning community may create an individual introductory video to emulate the traditional face-to-face classroom atmosphere [5], [7], [29]. Additionally, a debate discussion and individual presentation can be accomplished by the creation of video to foster a better student-student interaction and deeper leaning experience. With the advance of technological innovation in the past few years, video production in the online education could be simple and easy. Videos can be created via smart phone, digital camera, or webcam on the laptop without additional cost.

Moreover, numerous screen capture software applications are available to produce studio-quality videos or other types of multimedia. Screen capture software enables the users to record from webcam, external devices, computer screen, or streaming video. Screen capture software applications come with different screen capture mode, and each has its own built-in editing functions [39]. Although the majority of screen capture software applications are sold at an affordable price, some firms offer free screen capture software to users [37], [39]. They are Bug Shooting, CaptureIt Plus, iWeSoft Screenshot Capture, Jing, Monosnap, Mr Shot, Screener, and Screencast-O-Matic.

Instructor's immediacy is the behavior that brings the instructor and the students closer together in terms of perceived distance [2], [10], [28], [38]. Multimedia provides an innovative and effective means to address the issue of 
physical and psychological distance existing in the online environment. The use of multimedia in the online learning environment can raise instructor's immediacy by allowing the non-verbal immediacy to be conveyed. Multimedia can stimulate students' interest and engage students for longer periods of time [5], [10]-[11], [33], [36]. The more interested and engaged students are, the more students will enjoy, learn, and retain information. The instructor's ability to engage students is so critical to adult learners who often struggle with school along with multiple obligations from job, family and other life commitments. Adult learners deserve a little bit extra assistance from the instructor to be successful in the online classrooms.

\section{CONCLUSION}

With the advances in communication technology, tools and techniques are available to minimize problems related to geographical distances and raise the level of social presence, teaching presence as well as instructor immediacy. Distance learners these days have several means to interact with their instructors and peers. Instructors who teach online courses have more tools such as multimedia to boost teaching presence through immediacy behaviors and improve the effectiveness of online learning.

\section{REFERENCES}

[1] S. Aragon, "Creating social presence in online environments," New Directions for Adult \& Continuing Education, vol. 100, pp. 57-68, Winter 2003.

[2] G. Cui, B. Lockee, and C. Meng, "Building modern online social presence: A review of social presence theory and its instructional design implications for future trends," Education Information Technologies, vol. 18, pp. 661-685, 2013.

[3] P. Leong, "Role of social presence and cognitive absorption in online learning environments," Distance Education, vol. 32, no 1, pp. 5-28, May 2011.

[4] L. A. Mayne and Q. Wu, "Creating and measuring social presence in online graduate nursing courses," Nursing Education Perspectives, vol. 32, no 2, pp. 110-114, 2011.

[5] H. Lu, "Using multimedia to enhance students' online learning," Western Journal of Human Resource Management, pp. 58-69, 2014.

[6] C. H. Tu and M. S. McIsaac, "The relationship of social presence and interaction in online classes," The American Journal of Distance Education, vol. 17, no. 3, pp. 131-150, 2002.

[7] C. Wei, N. Chen, and KInshuk, "A model for social presence in online classrooms," Education Technology Research and Development, vol. 60, pp. 529-545, 2012.

[8] E. K. Cakmak, A. Cebi, and A. Kan, "Developing a 'social presence scale' for e-learning environments," Educational Sciences: Theory \& Practice, vol. 14, no. 2, pp. 764-768, 2014.

[9] C. Xin, "A critique of the community of inquiry framework," The Journal of Distance Education, vol. 26, no. 1, pp. 1-15, 2012.

[10] P. J. Draus, M. J. Curran, and M. S. Trempus, "The influence of instructor-generated video content on student satisfaction with and engagement in asynchronous online classes," MERLOT Journal of Online Learning and Teaching, vol. 10, no 2, pp. 240-254, June 2014.

[11] F. Leow and M. Neo, "Interactive multimedia learning: Innovating classroom education in a malaysian university," The Turkish Online Journal of Educational Technology, vol. 31, no. 2, pp. 99-110, 2014.

[12] S. Gallagher-Lepak, J. Reilly, and C. M. Killion, "Nursing student perceptions of community in online learning," Contemporary Nurse, vol. 32 , no. 1-2, pp. 133-146, 2009.

[13] D. Conrad, "Building and maintaining community in cohort-based online learning," Journal of Distance Education, vol. 20, no. 1, pp. 1-20, 2005.

[14] P. Shea, C. S. Li, K. Swan, and A. Pickett, "Developing learning community in online asynchronous college courses: The role of teaching presence," Journal of Asynchronous Learning Networks, vol. 9, no. 4, pp. 59-82, 2002.

[15] K. Swan and P. Shea, "The Development of Virtual Learning Communities," Asynchronous Learning Networks, New York, NY: Hampton Press, 2005, pp. 239-260.

[16] A. P. Rovai, "Building and sustaining community in asynchronous learning networks," The Internet and Higher Education, vol. 3, no. 4, pp. 285-297, 2000.

[17] M. Argyle and J. Dean, "Eye-contact, distance and affiliation," Sociometry, vol. 28, no. 3, pp. 289-304, Sep. 1965.

[18] M. Wiener and A. Mehrabian, Language within Language: Immediacy, a Channel in Verbal Communication, New York, NY: Appleton-Century-Crofts, 1968.

[19] J. Short, E. Williams, and B. Christie, The Social Psychology of Telecommunications, London: Wiley, 1976.

[20] D. R. Garrison, T. Anderson, and W. Archer, "Critical inquiry in a text-based environment: Computer conferencing in higher education," The Internet and Higher Education, vol. 2, no. 2-3, pp. 87-105, 2000.

[21] L. Polhemus, L. F. Shih, J. C. Richardson, and K. Swan, "Building an effective learning community: Social presence and learning engagement," presented at the World Conference on the WWW and the Internet, 2000.

[22] A. Picciano, "Beyond student perceptions: issues of interaction, presence, and performance in an online course," Journal of Asynchronous Learning Networks, vol. 6, no. 1, pp. 21-40, 2002.

[23] J. C. Richardson and K. Swan, "Examining social presence in online courses in relation to students' perceived learning and satisfaction," Journal of Asynchronous Learning Networks, vol. 7, no.1, pp. 68-88, 2003.

[24] T. Russo and S. Benson, "Learning with invisible others: Perceptions of online presence and their relationship to cognitive and affective learning," Educational Technology \& Society, vol. 8, no. 1, pp. 54-62, 2005.

[25] S. C. Cobb, "Social presence, satisfaction, and perceived learning of RN-to-BSN students in web-based nursing courses," Nursing Education Perspectives, vol. 32, no. 2, pp. 115-119, March/Apr 2011.

[26] L. J. Rifkind and L. F. Harper, "Competent verbal and nonverbal cross gender immediacy behavior," CUPA Journal, vol. 44, no. 2, pp. 47-54, 1993.

[27] M. Huang, W. Hsiao, and T. Chang, "Design and implementation of a cooperative learning system for digital content design curriculum: Investigation on learning effectiveness and social presence," The Turkish Online Journal of Educational Technology, vol. 11, no. 4, pp. 94-106, October 2012.

[28] A. A. Ghamdi, A. Samarji, and A. Watt, "Essential considerations in distance education in KSA: Teacher immediacy in a virtual teaching and learning environment," International Journal of Information and Education Technology, vol. 6, no. 1, pp. 17-22, January 2016.

[29] M. Griffiths and C. Graham, "Using asynchronous video in online classes: Result from a pilot study," Instructional Technology and Distance Learning, vol. 6, no. 3, pp. 65-75, 2009.

[30] C. N. Gunawardena and M. S. Mclsaac, "Distance education," Handbook of Research for Educational Communications and Technology, Bloomington, IN: Association for Educational Communications \& Technology, 2004, pp. 355-395.

[31] J. Koh, Y. Kim, B. Butler, and G. Bock, "Encouraging participation in virtual communities," Communications of the ACM, vol. 50, no. 2, pp. 68-73, 2007.

[32] M, Rusli, I. W. Ardhana, I. N. Sudana, and W. Kamdi, "Learning with invisible others: Perceptions of online presence the effect of presentation strategy on multimedia learning-animation vs static visualization-and learning style to learning result," Academic Research International, vol. 5, no. 1, pp. 216-221, 2014.

[33] Y. W. Li, "Transforming conventional teaching classroom to learner-centred teaching classroom using multimedia-mediated learning module," International Journal of Information and Education Technology, vol. 6, no. 2, pp. 105-112, February 2016.

[34] W. Sugar, "Development and formative evaluation of multimedia case studies for instructional design and technology student," Tech. Trends, vol. 58, no. 5, pp, 37-48, 2014

[35] M. Zaidel, and X. Luo, "Effectiveness of multimedia elements in computer supported instruction: Analysis of personalization effects, students performances and costs," Journal of College Teaching and Learning, vol. 7, no. 2, pp 11-16, Feburary 2012.

[36] S. Ryman, L. Burrell, G. S. Ryman, L. Burrell, G. Hardham, B. Richardson, and J. Ross, "Creating and sustaining online learning communities: Designing for transformative learning," International Journal of Pedagogies and Learning, vol. 5, no. 3, pp. 32-45, 2009. 
[37] H. Lu, "The impact of using multimedia on students' learning in the online classroom," in Proc. Global Learn 2015, Berlin Germany, 2015, pp. 671-674.

[38] K. Plante and M. E. Asselin, "Best practices for creating social presence and caring behaviors online," Nursing Education Perspectives, vol. 35, no. 4, pp. 219-223, 2014.

[39] I. Bansal. (January 26, 2010). 5 best free screen capture software. [Online].

Available:

http://www.ilovefreesoftware.com/26/articles/5-best-free-screen-capt ure-software.html

Hwangji S. Lu holds two master's in nutrition from North Dakota State University in Fargo ND and health services administration from Center Michigan University in Mount Pleasant MI of the USA. She earned her PhD in management with a specialization in leadership and organizational change from Walden University in Minneapolis, MN.
Currently, she is a remote assistant professor in the master's program of healthcare administration at Ashford University located in San Diego, CA. Apart from Ashford University, she have taught online courses at a number of universities since 2006. Prior to this post, she had over 20 years of professional experiences in various industries, inside and outside the healthcare arena. Her research interests include leadership development and using innovated technology in the online education.

Dr. $\mathrm{Lu}$ is a member of professional societies such as Academy of Management, Southern Management Association, Multimedia Educational Resource for Learning and Online Teaching, and International Economics Development and Research Center. Dr. Lu was awarded as a 2008 Outstanding Reviewer by the Academy of Management Health Care Management Division. Dr. Lu was named as the recipients of Provost's Circle Award at a couple of universities in 2009 and 2010. 